www.jmscr.igmpublication.org

Impact Factor 5.84

Index Copernicus Value: 71.58

ISSN (e)-2347-176x ISSN (p) 2455-0450

crossref DOI: _https://dx.doi.org/10.18535/jmscr/v5i9.29

\title{
Lobulated Epidermoid Cyst in the Extra Capsular Region of Parotid Gland: A Case Report
}

\author{
Authors
Narendra Babu B K
, \\ ${ }^{1}$ Oral \& Maxillofacial Surgeon, Indian Army Dental Corps \\ ${ }^{2}$ Cardiothoracic Surgeon, Indian Armed Forces Medical Services \\ ${ }^{3}$ Pathologist, Indian Armed Forces Medical Services \\ ${ }^{4}$ Radiologist, Indian Armed Forces Medical Services
}

\begin{abstract}
Cystic swellings are common in the craniofacial region. The majority are subcuticular in nature, they may present as nodular and fluctuant lesions and are seen most frequently in the hair bearing region of head and neck. The most common cause is the inflammation of the hair follicle and rarely following the implantation of the epithelium, subsequent to a trauma or surgery. We are reporting a rare case of epidermoid cyst in the parotid region of a 31-year-old African male. A diagnosis of an epidermoid cyst was given on cytological examination and confirmed by the histopathological study.
\end{abstract}

\section{INTRODUCTION}

Literature review reveals epidermoid cysts are rare lesions with an incidence of $6.9 \%$ in skin and $1.6 \%$ in oral cavity ${ }^{[1][2]}$. They are asymptomatic, slow growing, firm-to-fluctuant, dome-shaped lesions that frequently appear on the scalp, face and neck region. A few case reports indicate rare occurrence of these cysts in non-follicular regions like palms or soles. Traumatic implantation of epidermis into the dermis or subcutis is the cause of formation of epidermal cysts in such unusual sites ${ }^{[3]}$. It occurs in a wide age group varying from birth to 70 years and frequently seen between $2^{\text {nd }}$ and $3^{\text {rd }}$ decade $^{[4]}$. They are common in males. These epithelial walled cysts vary from a few millimeters to $5 \mathrm{~cm}$ in diameter. The cysts are mobile unless fibrosis is present. Historically, epidermoid cysts have been referred to by various terms, including infundibular cysts, epidermal cysts, and epidermal inclusion cysts and sebaceous cyst. The diagnosis of epidermoid cyst in the parotid region is essential as it mimics presentation of a parotid abscess, neoplasm, and other cysts. Therefore, an FNAC, USG and other radiological investigation are necessary for a prompt diagnosis and treatment.

\section{CASE HISTORY}

A 31year-old African male patient presented to our centre with a complaint of swelling on the right side of the face in front of the ear past eighteen months. The swelling was insidious in onset and steadily progressed to reach the current size. There was no history of pain, fever, or any discharge from the swelling. There was also no history of trauma or any previous surgeries 
reported in the facial region. On regional examination, there was a localized ovoid swelling in the right preauricular region. The swelling was $4 \times 3 \mathrm{~cm}$ approx in size and extended around 1.5 $\mathrm{cm}$ approx below the lobule of the right ear. The colour of the skin overlying the swelling was normal with no secondary changes. Fig 1.

On palpation, the swelling was soft in consistency, nontender, and nonpulsatile and was movable below the skin. There was no neurosensory discrepancy in relation to $7^{\text {th }}$ cranial nerve. General physical examination was done to rule out swellings in the other parts of the body. None was found.

Ultrasound was carried out and it revealed hypoechoic lesion in the extracapsular region of parotid region measuring $3.7 \times 3.2 \mathrm{~cm}$. The lesion was well encapsulated with no internal vascularity and no evidence of calcification. Internal contents didn't exhibit any motion, Suggestive of thick debris. A provisional diagnosis of epidermoid cyst was given. Fine Needle Aspiration Cytology (FNAC) was advised, the smear from the aspirate showed only anucleated squames in a proteinceous background. The cytologic examination confirmed the diagnosis of epidermoid cyst.

Patient underwent surgical intervention under general anaesthesia. Endaural incision was planned, the incision continued under the lobe of the ear and approximately $5 \mathrm{~mm}$ onto the posterior surface of the auricle. Blunt dissection was carried out to expose the cyst, on completion of the dissection from surrounding tissues, it was found to be lobulated and lying superficial to parotid capsule. Fig 2.

The cyst was removed in total and gross examination revealed a lobular sac with a septa, measuring $4.8 \times 3.5 \mathrm{~cm}$ in size and cut surface showed cheesy oily material. Fig 3 . Sections were made and histopathological examination revealed hyperkeratotic epidermis. Cyst was filled sheets of keratin, anucleated squamous cells with giant cell reaction, minimal neutrophilic infiltrates and area of mature cartilage. No Atypia was seen. Fig 4. Post operatively the healing was uneventful and regular follow up for a year showed no signs of recurrence.

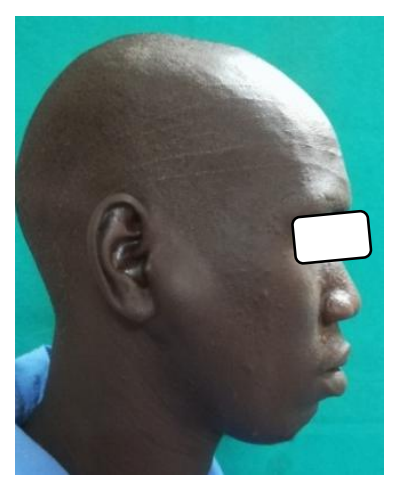

Figure no.1

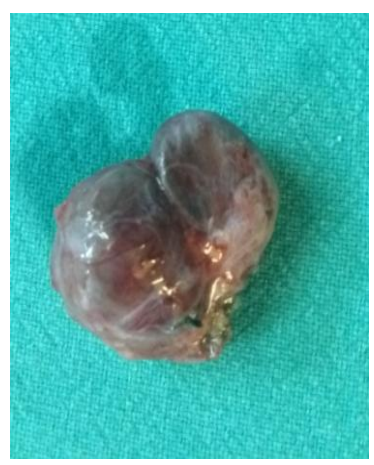

Figure no.3

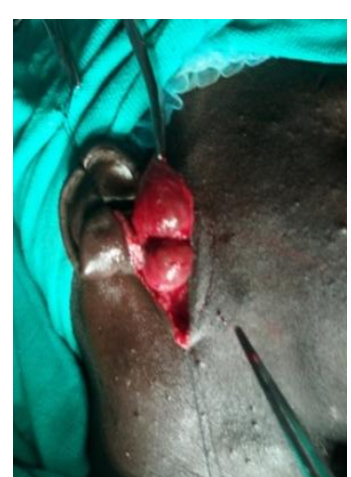

Figure no.2

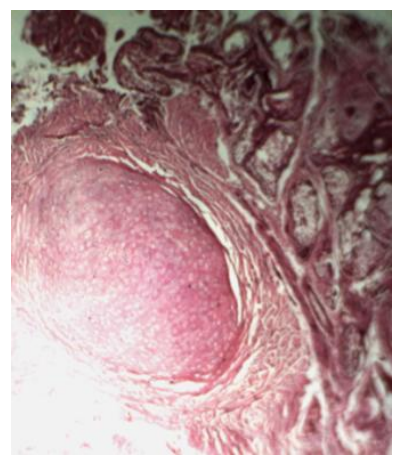

Figure no. 4

\section{DISCUSSION}

Epidermal cysts are less commonly seen dermatological lesions that consist of epithelial lined cavities filled with viscous or semisolid epithelial degradation products. The various terms used to describe this cyst are infundibular cysts, epidermal cysts, and epidermal inclusion cysts and sebaceous cyst. The term infundibular cyst refers to the site of origin of the cyst, the infundibular portion of the hair follicle and epidermal inclusion cyst is the result of the implantation of epidermal elements in the dermis. Because most lesions originate from the follicular infundibulum, the more general term epidermoid cyst is favored ${ }^{[5]}$. The term sebaceous cyst is a misnomer, as it implies that the cyst is of sebaceous origin. They usually arise secondary to obstruction or secondary to traumatic implantation of epithelial fragments while dermoid cysts arise from developmental epithelial remnants. These are usually painless swellings without any attachment to the overlying skin or involvement of facial 
nerve. However, it may become symptomatic due to secondary infection that can cause damage to the surrounding anatomical structures ${ }^{[6]}$.

The differential diagnosis should include swellings occurring in and around the parotid region, which may include branchial cleft cyst which is "congenital", or may be "acquired" due to inflammation, abscess, obstruction, neoplasm, calculi, and trauma. They can develop in isolation or multifocal form, as can be seen in Gardner's syndrome ${ }^{[7]}$. Diagnosis is frequently by imaging and aided by fine needle aspiration cytology, followed by excision biopsy.

FNAC of skin lesion is without doubt a quickest and fastest technique that provides important information in papulonodular lesions. This technique is sometimes preferable to biopsy in facial region to avoid or minimize scarring. FNAC is useful in differentiating benign from malignant tumour and also in diagnosing primary skin tumour. Some of the lesions that can be diagnosed on FNAC include epidermal inclusion cyst, trichilemmal cyst and various skin adnexal tumours. FNAC is a procedure that is economical, quick, and a less traumatic procedure to diagnose nodular lesions of skin ${ }^{[8]}$.

Ultrasound is a very important diagnostic modality to explore swellings in craniofacial region; it enables to perform early diagnosis and provides precise anatomical information which enables to adequately plan the surgical procedures. Epidermal cysts have the typical characteristics of cysts; i.e, they have a round to oval structure along with the phenomena of dorsal acoustic amplification and lateral shadowing. They also show central echoes of nonanechoic intensity owing to their contents as well as partial indentation to the dermis when they are subcutaneous $^{[9]}$. Ultrasound is a non-invasive diagnostic method, without ionizing radiation which is adequate for diagnosis and follow-up.

The treatment of epidermoid cyst is excision. Depending on the location, appropriate surgical approach has to be used to gain adequate access and hide scar in the facial creases. In our case,
Endaural incision ${ }^{(10)}$ was used, since the swelling had obliterated the preauricular skin fold, the incision was further extended under the lobe of the ear and approximately $3 \mathrm{~mm}$ onto the posterior surface of the auricle. This approach is useful especially in young patients, who do not have a well-demarcated preauricular skin fold and also for individuals prone for keloid formation. Post auricular extension of the incision prevents a noticeable scar that occurs during contractive healing of the flap, pulling the scar into the neck. Precaution should be taken not to rupture the cyst which can lead to postoperative inflammation of the surrounding tissues. Recurrence rate is low.

\section{CONCLUSION}

Literature review reveals epidermoid cyst of the parotid gland is uncommon, with merely not many cases having being reported in the journals. Our case is unique, the cyst was lobulated with a septa dividing the cystic space and lying superficial to parotid capsule without any adhesion to it. A cartilaginous component along with other contents was found in the cystic cavity. Epidermal cysts must be considered as a differential diagnosis in asymptomatic chronic enlargements of parotid gland which is pliable and fluctuant in consistency.

\section{REFERENCES}

1. Koca H, Seckin T, Sipahi A, Kaznac A (2007) Epidermoid cyst in the floor of the mouth: report of a case. Quintessence Int 38: 473-477.

2. Fisher BK, Macpherson M. Epidermoid cyst of the sole. J Am Acad Dermatol. 1986;15: 1127-9.

3. Ozan F, Polat HB, Ay S, Goze F (2007) Epidermoid cyst of the buccal mucosa: a case report. J Contemp Dent Pract 3:9096.

4. Jose Carlos Garcia de Mendonça, Ellen Cristina Gaetti Jardim, Cauê Monteiro dos Santos, Danilo Chizzolini Masocatto, Diones Calado de Quadros, Murilo Moura 
Oliveira, Juliana Andrade Macena, and Fernando Ribeiro Teixeira "Epidermoid Cyst: Clinical and Surgical Case Report", Ann Maxillofac Surg 2017, Jan-Jun; 7(1):151-154.

5. P. N. Hegde, H. L. Kishan Prasad, Y. Sunil Kumar et al., "A rare case of an epidermoid cyst in the parotid gland which was diagnosed by fine needle aspiration cytology," Journal of Clinical and Diagnostic Research, vol. 7, no. 3, pp. 550-552, 2013.

6. M. Streppel, J. P.Thomas, E. Stennert, O. Guntinas-Lichius, and M. Wagner, "Infected epidermoid cyst as cause of peripheral facial palsy. A case report," Laryngo-Rhino-Otologie, vol. 80, no.10, pp. 617-619, 20.

7. H. G. Burkitt, C. R. G. Quick, and D. T. Gatt, Essential Surgery:Problems, Diagnosis and Management, Churchill Livingstone, Langmans, 1990.

8. Sapna Patel, Asha Mahadevappa, and Gubbanna Vimalambike Manjunath. Fine Needle Aspiration Cytology of Papulonodular Lesions of Skin: A Study of 50 Cases. J Clin Diagn Res 2016: 10(12)

9. Kuwano Y, Ishizaki K, Watanabe R, et al. Efficacy of diagnostic ultrasonography of lipomas, epidermal cysts, and gangl-ions. Arch Dermatol. 2009; 145:761-4.

10. Surgical approaches to facial skeleton. Edward Ellis, Michael F.Zide :182-183. 